\title{
Good Governance, Kompetensi SDM, Budaya Organisasi dan Kinerja Pengelolaan Dana Desa
}

\author{
Ayu Ariani ${ }^{1}$ \\ Fakultas Ekonomi dan Bisnis \\ Universitas Udayana, Indonesia
}

\author{
Gayatri ${ }^{2}$ \\ Fakultas Ekonomi dan Bisnis \\ Universitas Udayana, Indonesia
}

\begin{abstract}
Surel : ayuariani1108@gmail.com
ABSTRAK

Tingginya tuntutan mengenai akuntabilitas pengelolaan dana desa yang harus menjadi prioritas utama pemerintah desa merupakan fenomena yang biasanya terjadi dalam lingkup pemerintah desa. Pemerintah desa tidak hanya menuntut kemampuan dan profesionalitas tetapi untuk saat ini lebih menekankan terwujudnya pemeriintah yang terbebas dari tindakan Korupsi, Kolusi dan Nepotisme (KKN). Adapun tujuan dari penelitian ini tentu saja untuk mengetahui pengaruh good governance, kompetensi sumber daya manusia, serta budaya organisasi pada kinerja pengelolaan dana desa di Kecamatan Mengwi. Penelitian ini menggunakan 75 sampel. Dalam mengumpulkan data, peneliti menggunakan metode angket yang disebar-luaskan kepada responden secara langsung. Teknik analisis data yang digunakan adalah Analisis Regresi Linier Berganda. Hasil dari penelitian menyatakan Good governance, Kompetensi SDM, serta Budaya Organisasi mempunyai pengaruh positif signifikan pada Kinerja Pengelolaan Dana Desa di Kecamatan Mengwi.
\end{abstract}

Kata Kunci: Good Governance; Kompetensi; Budaya; Kinerja.

\section{Good Governance, HR Competence, Organizational Culture and Performance of Village Fund Management}

\begin{abstract}
The high demand for accountability in the management of village funds which must be the top priority of the village government is a phenomenon that usually occurs within the scope of village government. Village government does not only demand capability and professionalism but for now emphasizes the realization of a government that is free from corruption, collusion and nepotism (KKN). The purpose of this study was to determine the effect of good governance, human resource competence, and organizational culture on the performance of village fund management in Mengwi District. This study used 75 samples. In collecting data, researchers used a questionnaire method that was distributed directly to respondents. The data analysis technique used is Multiple Linear Regression Analysis. The results showed that Good governance, Human Resource Competence, and Organizational Culture had a significant positive effect on the Performance of Village Fund Management in Mengwi District.
\end{abstract}

Keywords: Good Governance; Competency; Culture; Performance.

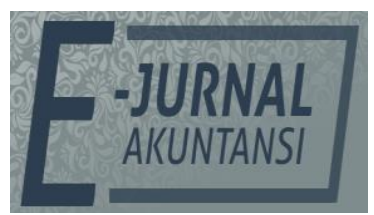

e-ISSN 2302-8556

Vol. 31 No. 10

Denpasar, Oktober 2021

Hal. 2481-2489

DOI:

10.24843/EJA.2021.v31.i10.p06

PENGUTIPAN:

Ariani, A., \& Gayatri. (2021).

Good Governance, Kompetensi

SDM, Budaya Organisasi dan

Kinerja Pengelolaan Dana

Desa. E-Jurnal Akuntansi,

31(10), 2481-2489

RIWAYAT ARTIKEL: Artikel Masuk: 11 Januari 2021 Artikel Diterima: 26 Maret 2021

Artikel dapat diakses : https://ojs.unud.ac.id/index.php/Akuntansi/index 


\section{PENDAHULUAN}

Tingginya tuntutan mengenai akuntabilitas pengelolaan dana desa yang harus menjadi prioritas utama pemerintah desa merupakan fenomena yang biasanya terjadi dalam lingkup pemerintah desa. Dengan adanya akuntabilitas dalam pemerintah diharapkan mampu memperbaiki kualitas beserta kinerja dari organisasi agar dapat berorientasi pada kepentingan publik (Wardiana \& Hermanto, 2019). Harapannya seluruh kebutuhan masyarakat desa dapat diakomodasi secara lebih baik supaya tercipta hubungan yang baik antara pemerintah dengan masyarakat seperti yang terkandung pada ketetapan UU No. 6 Tahun 2014.

Pengelolaan organisasi pemerintahan bisa dikatakan berakar pada prinsip tata kelola yang baik, diharapkan membawa dampak yang baik untuk kemajuan organisasi itu sendiri. Dengan diwujudkannya tata kelola pemerintah yang baik, maka pengelolaan keuangan desa dapat dikelola dengan prinsip tata kelola yaitu transparan, akuntabel dan partisipatif serta dilakukan dengan tertib dan disiplin anggaran (Ardiyanti \& Supriadi, 2018) Pengelolaan dana desa didalam pemerintahan desa, dikelola oleh aparatur bagian keuangan desa. Pihak aparatur pemerintah desa yang mengelola keuangan desa diharapkan berkompeten dalam menjalankan tugasnya dalam mencapai tujuan. Kompetensi sumber daya manusia (SDM) ialah skill seseorang yang bekerja dengan ilmu pengetahuan dan keterampilan yang dimiliki dengan sebaik mungkin, ditambah dengan pengalaman dan keterampilan dalam mengeksplore diri dapat menunjang individu untuk meningatkan kualitas yang ada dalam dirinya. Hal ini didukung oleh hasil penelitian (Agustiningsih et al., 2020) yang menjelaskan bahwa kompetensi pendamping desa memiliki dampak positif pada keberhasilan pengelolaan dana desa. Kompetensi SDM dalam suatu organisasi bisa disebut sebagai sebuah pondasi dalam organisasi, kuat atau lemahnya kinerja suatu organisasi bergantung dari kokoh atau tidaknya pondasi yang digunakan untuk mendirikan organisasi itu sendiri. Sumber daya manusia yang memiliki kualitas dapat terlihat dari tingkat pendidikan, kesesuaian tugas latar belakang pendidikan, serta kecepatan dan ketepatan dalam pelaksanaan tugas (Putri 2019).

Kompetensi SDM yang terdapat pada organisasi pemerintah biasanya mampu mencerminkan bagaimana budaya yang diterapkan dalam organisasi tersebut. Segala tingkah laku anggota instansi sangat dipengaruhi oleh budaya organisasi yang telah tercipta dalam organisasi tersebut. Semakin positif budaya organisasi yang tercipta maka dapat dikatakan mampu mendorong organisasi menjadi lebih baik (Purbasari et al., 2020). Budaya organisasi merupakan kebiasaan seseorang yang dapat berpengaruh terhadap kinerja dalam instansi atau suatu organisasi. Hal ini didukung dengan penelitian (Widiyarta et al., 2018) dan (Agustiningsih et al., 2020) menyatakan bahwa budaya organisasi berdampak positif terhadap keberhasilan penyerapan dana desa.

Teori agensi (agency theory) merupakan kumpulan kontrak (nexus of contract) antara pemilik sumber daya ekonomis (principal) dan manajer (agent) yang mengurus penggunaan dan pengendalian sumber daya tersebut (Jensen \& Meckling, 1976). Teori ini juga sering diterapkan pada sektor publik atau pemerintahan. Implikasi teori keagenan dalam penelitian ini yaitu menggambarkan korelasi antara pemerintah desa (agen) yang bertugas mengelola 
keuangan desa yang nantinya akan dipertanggungjawabkan kepada pemerintah daerah yang bertindak sebagai (principal). Pemerintah desa sudah barang tentu harus mampu mempertanggungjawabkan dana yang diperoleh untuk menciptakan kesejahteraan masyarakat.

Penerapan good governance dapat meningkatkan kinerja, dengan penerapan good governance yang baik dalam organisasi sektor publik maka dapat membantu aparatur pemerintahan dalam pengambilan keputusan antar berbagai pihak yang berwenang (Widasari, 2018) dalam penelitiannya (Nasrun, 2018) mendapatkan hasil, penerapan good governance dalam organisasi mempunyai pengaruh pada kinerja keuangan pemerintahan daerah. Berdasarkan hal tersebut peneliti menetapkan hipotesis sebagai berikut.

$\mathrm{H}_{1}$ : Good governance memiliki pengaruh positif dan signifikan pada kinerja pengelolaa dana desa di Kecamatan Mengwi.

Kompetensi dari SDM yang bekerja dalam suatu instansi pemerintah dapat dijadikan alat ukur yang mengacu pada tingkat keberhasilan instansi dalam pencapaian tujuan (Putri, 2019). Penelitian yang dilakukan (Agustiningsih et al., 2020) dan (Nurhazizal et al., 2019) memperlihatkan hasil bahwa adanya kompetensi SDM yang baik serta berkualitas dapat memudahkan pengelolaan dana desa yang tentunya akan berdampak terhadap kinerja instansi dalam pencapaian tujuan. Kompetensi sumber daya manusia merupakan pondasi yang mencerminkan keberlangsungan instansi dalam menjalankan tugasnya kedepannya. Berdasarkan hal tersebut peneliti menetapkan hipotesis sebagai berikut.

$\mathrm{H}_{2}$ : Kompetensi SDM memiliki pengaruh positif pada kinerja pengelolaan dana desa di Kecamatan Mengwi.

Menurut (Yamin, 2014) dalam (Putri \& Raheni, 2019) budaya organisasi merupakan kebiasaan-kebiasaan yang terjadi dalam suatu organisasi yang mewakili norma-norma perilaku dan diikuti oleh para anggota dalam organisasi, maka budaya organisasi akan memberikan suasana psikologis bagi semua anggota. Penelitian oleh (Putri \& Raheni, 2019) dan (Widasari, 2018) menyatakan hasil yakni budaya organisasi memiliki pengaruh yang positif pada kinerja pemerintahan daerah. Ketika budaya organisasi yang tercipta dalam suatu organisasi semakin membaik, maka dikatakan dapat menaikkan kinerja manajerial penyelenggara pemerintah. Berdasarkan hal tersebut peneliti menetapkan hipotesis sebagai berikut.

$\mathrm{H}_{3}$ : Budaya organisasi memiliki pengaruh positif pada kinerja pengelolaan dana desa di Kecamatan Mengwi.

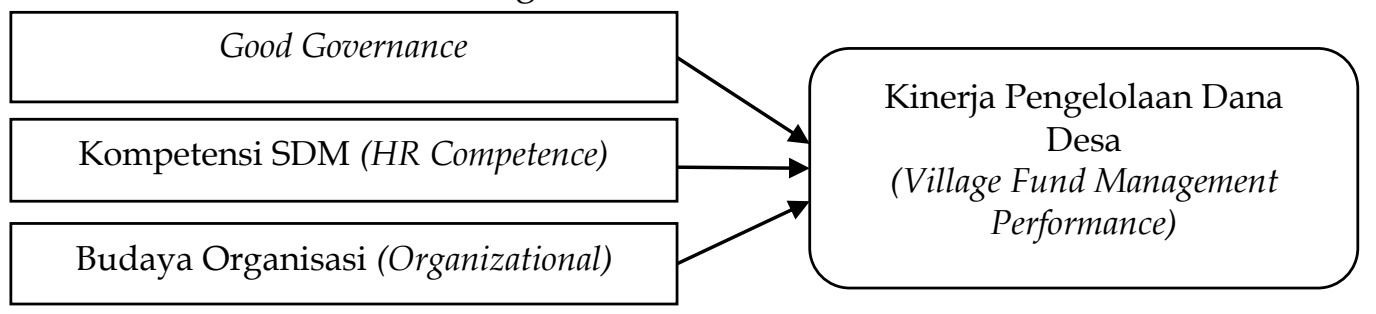

Gambar 1. Model Penelitian

Sumbe: Data Peneliti, 2020 


\section{METODE PENELITIAN}

Penelitian menggunakan variabel dependen yakni Kinerja Pengelolaan Dana Desa $(\mathrm{Y})$, dan variabel independennya yaitu Good governance $\left(\mathrm{X}_{1}\right)$, Kompetensi SDM $\left(\mathrm{X}_{2}\right)$ serta Budaya Organisasi $\left(X_{3}\right)$. Adapun populasi yang digunakan yakni perangkat desa yang ada pada desa-desa se-Kecamatan Mengwi, dengan mengambil sampel sejumlah 75 orang.

Teknik analisis regresi linear berganda dilakukan guna mendapatkan hasil analisis mengenai pengaruh good governance, kompetensi SDM, serta budaya organisasi pada kinerja pengelolaan dana desa. Adapun model analisis regresi linier bergandanya adalah sebagai berikut.

$Y=\alpha+\beta_{1} X_{1}+\beta_{2} X_{2}+\beta_{3} X_{3}+\varepsilon$

Keterangan:

Y $\quad$ : Kinerja Pengelolaan Dana Desa

a : Constanta

$\mathrm{X}_{1} \quad$ : Good governance

$\mathrm{X}_{2} \quad$ : Kompetensi SDM

$\mathrm{X}_{3} \quad$ : Budaya Organisasi

B $\quad$ : Koefisien regresi untuk masing-masing variabel independen

$\varepsilon \quad$ : Standar Error

\section{HASIL DAN PEMBAHASAN}

Menurut (Sugiyono, 2017) uji asumsi klasik digunakan untuk mendeteksi ada atau tidaknya penyimpangan asumsi klasik atau persamaan regresi berganda yang digunakan, pengujian ini terdiri atas uji normalitas, uji multikolinearitas dan uji heteroskedastisitas. Hasil dari uji asumsi klasik pada penelitian ini diolah menggunakan software SPSS 21 for Windows, masing-masing dijabarkan sebagai berikut.

Tabel 1. Hasil Uji Normalitas

\begin{tabular}{lll}
\hline & & Unstandardized Residual \\
\hline $\mathrm{N}$ & 75 & \\
Kolmogorov-Smirnov Test & 0,077 & \\
Asymp. Sig. (2-tailed) & 0,200 & \\
\hline
\end{tabular}

Sumber: Data Penelitian, 2020

Hasil uji normalitas yang tersaji pada Tabel 1, memperlihatkan nilai Kolmogorov-Smirnov adalah 0,077 serta nilai asymp.sig (2-tailed) $>0,05$ yaitu sebesar 0,200 , jadi data yang diuji memiliki penyebaran normal atau berdistribusi dengan normal.

Tabel 2. Hasil Uji Multikolinearitas

\begin{tabular}{lcc}
\hline Variabel & \multicolumn{2}{c}{ Collinearity Statistics } \\
\cline { 2 - 3 } & Tolerance & VIF \\
\hline Good governance & 0,916 & 1,091 \\
Kompetensi SDM & 0,980 & 1,020 \\
Budaya Organisasi & 0,933 & 1,072 \\
\hline
\end{tabular}

Sumber: Data Penelitian, 2020

Hasil uji multikolinearitas yang disajikan pada Tabel 2, memperlihatkan variabel good governance mempunyai nilai tolerance $0,916>0,10$ serta nilai VIF 1,091 $<10$. Variabel kompetensi SDM memiliki nilai tolerance $0,980>0,10$ serta nilai VIF 
$1,020<10$. Variabel budaya organisasi memiliki nilai tolerance $0,933>0,10$ serta nilai VIF $1,072<10$. Hal ini menunjukkan, ketiga variabel bebas pada model regresi, bebas dari gejala multikolinearitas.

\section{Tabel 3. Hasil Uji Heteroskedastisitas}

\begin{tabular}{lll}
\hline \multicolumn{1}{c}{ Variabel } & Sig. \\
\hline Good governance & 0,657 & \\
Kompetensi SDM & 0,151 & \\
Budaya Organisasi & 0,193 & \\
\hline
\end{tabular}

Sumber: Data Penelitian, 2020

Hasil uji heteroskedastisitas yang disajikan dalam Tabel 3, memperlihatkan variabel good governance memiliki Sig. sebesar 0,657, kompetensi SDM memiliki Sig. sebesar 0,151, serta budaya organisasi memiliki Sig. sebesar 0,193. Apabila diperbandingkan dengan nilai signifikansi setiap variabel bebas, seluruhnya $>$ 0,05, sehingga variabel bebas pada model regresi bebas dari gejala heteroskedastisitas. Menurut (Sugiyono, 2017) analisis regresi linear berganda digunakan bila peneliti bermaksud meramalkan bagaimana keadaan variabel dependen, bila dua atau lebih variabel independen sebagai faktor prediktor dimanipulasi.

Tabel 4. Hasil Analisis Regresi Linier Berganda

\begin{tabular}{|c|c|c|c|c|c|c|}
\hline \multirow{2}{*}{\multicolumn{2}{|c|}{ Variabel }} & \multicolumn{2}{|c|}{ Unstandardized Coefficients } & \multirow{2}{*}{$\begin{array}{l}\text { Standardized } \\
\text { Coefficients } \\
\text { Beta }\end{array}$} & \multirow[t]{2}{*}{$t$} & \multirow[t]{2}{*}{ Sig. } \\
\hline & & B & Std. Error & & & \\
\hline \multirow[t]{5}{*}{1} & (Constant) & 0,162 & 3,222 & & 0,050 & 0,960 \\
\hline & Good governance & 0,295 & 0,092 & 0,340 & 3,221 & 0,002 \\
\hline & Kompetensi SDM & 0,234 & 0,105 & 0,228 & 2,233 & 0,029 \\
\hline & Budaya & 0,299 & 0,111 & 0,283 & 2,708 & 0,008 \\
\hline & Organisasi & & & & & \\
\hline & iabel Dependen : & erja $P$ & Dana Des & & & \\
\hline
\end{tabular}

Sumber: Data Penelitian, 2020

Dari hasil analisis regresi linier berganda dapat dibentuk persamaan sebagai berikut.

$$
\mathrm{Y}=0,162+0,295 \mathrm{X}_{1}+0,234 \mathrm{X}_{2}+0,299 \mathrm{X}_{3}+\varepsilon
$$

Nilai konstanta a yaitu 0,162 memiliki arti apabila nilai good governance $\left(\mathrm{X}_{1}\right)$, kompetensi SDM $\left(X_{2}\right)$ dan budaya organisasi $\left(X_{3}\right)$ dianggap konstan pada nilai 0 (nol), maka nilai kinerja pemerintah desa $(Y)$ adalah sebesar 0,162.

Nilai koefisien Good governance $\left(X_{1}\right)$ yaitu 0,295 memiliki arti good governance mempunyai hubungan positif pada kinerja pemerintah desa. Apabila good governance $\left(\mathrm{X}_{1}\right)$ meningkat sebesar satu satuan maka tingkat kinerja pemerintah desa (Y) akan meningkat pula sebesar 0,295, jika diasumsikan variabel bebas lainnya bernilai konstan. $\mathrm{H}_{1}$ yang diajukan menyatakan, good governance mempunyai pengaruh yang positif pada kinerja pengelolaan dana desa. Hasil dari penelitian memperlihatkan bahwa good governance mempunyai koefisien regresi sebesar 0,295 dan nilai signifikansi yakni $0,002<$ a $(0,05)$, berarti variabel good governance mempunyai pengaruh pada kinerja pengelolaan dana desa. Hasil tersebut membuktikan $\mathrm{H}_{1}$ yang menyatakan good governance berpengaruh positif terhadap kinerja pengelolaa dana desa di Kecamatan Mengwi, terbukti kebenarannya atau $\mathrm{H}_{1}$ pada penelitian ini diterima. 
Kompetensi SDM $\left(\mathrm{X}_{2}\right)$ yaitu 0,234 memiliki arti bahwa kompetensi SDM mempunyai hubungan positif pada kinerja pemerintah desa. Apabila kompetensi $\operatorname{SDM}\left(\mathrm{X}_{2}\right)$ meningkat sebesar satu satuan maka tingkat kinerja pemerintah desa $(\mathrm{Y})$ akan meningkat pula sebesar 0,234, jika diasumsikan variabel bebas lainnya bernilai konstan. $\mathrm{H}_{2}$ yang diajukan menyatakan kompetensi SDM mempunyai pengaruh yang positif pada kinerja pengelolaan dana desa. Hasil penelitian memperlihatkan kompetensi SDM mempunyai koefisien regresi yakni 0,234, nilai signifikansinya sebesar $0,029<a(0,05)$ yang memiliki arti variabel kompetensi SDM memiliki pengaruh terhadap kinerja pengelolaan dana desa. Hasil tersebut membuktikan $\mathrm{H}_{2}$ yang menyatakan kompetensi SDM berpengaruh positif terhadap kinerja pengelolaa dana desa di Kecamatan Mengwi, terbukti kebenarannya atau $\mathrm{H}_{2}$ pada penelitian ini diterima. Hasil ini menunjukkan semakin tingginya tingkat kompetensi SDM dalam pemerintahan desa, maka semakin meningkatkan kinerja pemerintah desa dalam pengelolaan dana desa itu sendiri.

Budaya organisasi $\left(X_{3}\right)$ yaitu 0,299 memiliki arti budaya organisasi mempunyai hubungan positif pada kinerja pemerintah desa. Apabila budaya organisasi $\left(\mathrm{X}_{3}\right)$ meningkat sebesar satu satuan maka tingkat kinerja pemerintah desa (Y) akan meningkat pula sebesar 0,299, jika diasumsikan variabel bebas lainnya bernilai konstan. $\mathrm{H}_{3}$ yang diajukan menyatakan budaya organisasi memiliki pengaruh yang positif pada kinerja pengelolaan dana desa. Hasil penelitian memperlihatkan budaya organisasi mempunyai koefisien regresi yaitu 0,299 dan nilai signifikansi yaitu $0,008<$ a $(0,05)$ yang berarti bahwa budaya organisasi mempunyai pengaruh pada kinerja pengelolaan dana desa. Hasil tersebut mampu membuktikan bahwa $\mathrm{H}_{3}$ yang menyatakan budaya organisasi berpengaruh positif terhadap kinerja pengelolaa dana desa di Kecamatan Mengwi, terbukti kebenarannya atau $\mathrm{H}_{3}$ diterima. Tingginya pengaruh budaya organisasi dalam pemerintahan desa, menyebabkan semakin meningkatnya pengaruh terhadap kinerja pemerintah desa dalam pengelolaan dana desa itu sendiri.

\section{SIMPULAN}

Good governance, kompetensi SDM, dan budaya organisasi mempunyai pengaruh yang positif pada kinerja pengelolaan atas dana desa. Hal tersebut menunjukkan bahwa, semakin baik pemahaman dan penerapan tentang good governance, kompetensi SDM dan budaya organsiasi maka kinerja pengelolaan dana desa semakin bagus atau semakin tinggi. Pemerintah desa se-Kecataman Mengwi harus meningkatkan pemahaman tentang tata kelola pemerintahan yang baik serta aturan-aturan baru yang diterapkan baik yang berhubungan dengan kinerja maupun tentang pengelolaan dana desa. Selain itu diberikannya pelatihan dan aktifnya aparatur pemerintah desa untuk mengikuti pelatihan dan pelajaran mandiri dapat meningkatkan kualitas SDM yang ada dalam pemerintah desa itu sendiri. Selain itu juga kegiatan yang melibatkan aparatur pemerintah desa dalam lingkup diluar kegiatan operasional desa, diupayakan lebih dioptimalkan supaya tidak menganggu atau memperlambat kegiatan operasional pemerintah desa.

\section{REFERENSI}

Agustiningsih, M., Taufik, T., \& Indrawati, N. (2020). Pengaruh Good governance 
Dan Kompetensi Sumber Daya Manusia Terhadap Pengelolaan Dana Desa (Studi Empiris Pada Desa Di Kecamatan Tambang, Kecamatan Kampar Dan Kecamatan Bangkinang Kota). Bilancia: Jurnal Ilmiah Akuntansi, 4(1), 80-91.

Aziiz, M. N., \& Prastiti, S. D. (2019). Faktor-Faktor Yang Mempengaruhi Akuntabilitas Dana Desa. Jurnal Akuntansi Aktual, 334.

Agus Wahyudi, Sutjipto Ngumar, dan Bambang Suryono. (2019). Faktor- faktor yang Mempengaruhi Kinerja Manajerial Perangkat Desa. JRAMB Sekolah Tinggi Ilmu Ekonomi Indonesia Yogyakarta. Vol.5. No.2.

Ajibolade, Solabomi O., \& Opeyemi Kehinde A. (2013.) The Influense of Organisational Culture and Budgetary Participation on Propensity to Create Budgetary Slack in Public Sector Organisastions. British Journal of Arts and Social Scieces, 13(1), 69-83.

Agustiningsih, Taufik, Indrawati. (2020). Pengaruh Good governance dan Kompetensi Sumber Daya Manusia terhadap Pengelolaan Dana Desa Jurnal Ilmiah Akuntansi Universitas Riau. Vo.4.No.1.

Akbar, S., Polettl-Huges, J.,El-Fatouri, R., Shah, S, Z, A., (2016). More on The Relationship Between Corporate Governance and Fiirm Performance in the UK: Evidance from the Aplication of GeneralizedMethod of Moment Estimation. Res, Int, Bus, Financ. 38, 417-429

Al-Ahdal Waleed M., Alsamhi Mohammed., H Farhan Najib H.S., \& Tabash Mosab I. (2020). The Impact of Corporate Governance on Financial Performance of Indian and GCC Listed Firm: An Empirical Investigation. Research in International Business and Finance 51.

Al-Malkawi, H, A, N., Pillai R., Bt Fadzli, F, H,. (2017). Corporate Governance Practices in Emerging Markets: The Case of GCC Countries. Econ, Model, 38, 133-141.

Budiati, Yuli. (2019). Pengaruh GCG Terhadap Kinerja Pengelolaan Dana Desa Dengan Moderasi Sistem Pengendalian Internal. Jurnal Ekonomi dan Keuangan Universitas Semarang. Vol.3. No.4, Pp 426-444.

Brownell, P., \& McInnes, J. M. (1983). Budgetary Participation, Motivation and Managerial Performance. Journal of Chemical Information and Modeling, 83(9), 1689-1699.

Chong, V. K., \& Strauss, R. (2017). Participative budgeting: The effects of budget emphasis, information asymmetry and procedural justice on slack additional evidence. Asia-Pacific Management Accounting Journal, 12(1), 181220.

Collins, F. (1978). The interaction of budget characteristics and personality variables with budgetary response attitudes. Accounting Review, 324-335.

Derfuss, K. (2009). Budget Slack: Some Meta Analytic Evidence. European $\begin{array}{llll}\text { Accounting } & \text { Review, } & \text { 203-239. }\end{array}$ https://doi.org/https://doi.org/10.1017/CBO97811074 15324.004

Darma Putra dan Rasmini. (2019). Pengaruh Akuntabilitas, Transparansi, dan Partisipasi Masyarakat Pada Efektivitas Pengelolaan Dana Desa. Jurnal Akuntansi Universitas Udayana. Vol.28.No.1, Hal.132-158.

Eka Putri 2019. (2019). Pengaruh Kejelasan Sasaran Anggaran, Sistem Pengendalian Internal, SDM dan Motivasi terhadap Kinerja Aparatur Desa di Kec. Singingi Hilir Kab. Kuantan Singingi. 10(1), 92-108. 
Ghozali, Imam. (2016). Aplikasi Analisis Multivariate Dengan Program IBM SPSS 23. Semarang: Badan Penerbit Universitad Diponegoro.

Hofrichter, D, A, \& Jr Spencer. L, M. (1996). Competencies: The Right Foundation for Effective Human Resources Management. Compensation and Benefit Review 28(6), Hal.21-24.

Harvey, M. E. (2015). The Effect Of Employee Ethical Ideology on Organizational Budget Slack: An Empirical Examination and Practical Discussion. Journal of Business E Economics Research, 13(1), 83-90.

Hui, $\mathrm{H}$ dan Islam. (2012). A Review of Literature on Contingency theory in Managerial Accounting. African Journal Of Bussines Management. Vol. 6 (5), pp. 5159- 5164

Hopwood, A.G. (1972). An Empirical Study of the Role of Accounting Data in Performance Evaluation. Journal of Accounting Research.Vol. 10:156182.

Indah Widasari dan Asri Dwija. (2018). Pengaruh Good governance dan Budaya Organisasi Terhadap Kinerja Manajerial Penyelenggara Pemerintah Desa di Kabupaten Badung. E-Jurnal Akuntansi. Vol.22.No.2, Hal.1308-1334.

Jensen, M. C., \& Meckling, W. H. (1976). Theory of the firm: Managerial behavior, agency costs and ownership structure. Journal of Financial Economics, 3(4), 305-360.

Kramer, S., \& Hartmann, F. (2014). How Top-down and Bottom-up Budgeting Affect, Budget Slack, and Performance through Social and Economic Exchange. Abacus, 50(3), 314-340

Luthfiani dan Asmony. (2020). Analisis Faktor-Faktor yang Mempengaruhi Akuntabilitas Pengelolaan Dana Desa di Kabupaten Lombok Tengah. EJurnal Akuntansi Universitas Mataram. Vo.30.No.7.

Licata, M., Strawser R. dan Welker R.A. (1986). Note on Participation in Budgeting and Locus of Control. The Accounting Review. Vol.:61. No. 1.

Mas Setra, Nur Diana, dan Afifudin. (2019). Pengaruh Akuntabilitas Pengelolaan dan Good governance Terhadap Peran Perangkat Desa Dalam Pengelolaan Keuangan Desa. E-JRA Universitas Islam Malang. Vol.08. No.01.

Nasrun, Muhammad. (2018). Pengaruh Good governance Terhadap Kinerja Keuangan Pemerintah Daerah Kabupaten Pangkajene dan Kepulauan. Jurnal Equilibrium Universitas Muhammadiyah Makassar. Vol.0. No.0, Hal. 1926.

Nurhazizal, Basri dan Nasir. (2019). Pengaruh Komitmen Organisasi, Budaya Organisasi, Gaya Kepemimpinan dan Kompetensi SDM terhadap Kinerja Pemerintah Desa. Jurnal Akuntansi Magister Akuntansi FEB Universitas Riau. Vo.8.No.1.

Ng'ang'a ,Muya James \& Justus Nyongesa. (2012). The Impact of Organisational Culture on Performance of Educational Institutions. International Journal of Business and Social Science, 3(8): 211-217.

Praba Dewi dan Gayatri. (2019). Faktor-Faktpr Yang Berpengaruh Pada Akuntabilitas Pengelolaan Dana Desa. E-Jurnal Akuntansi Universitas Udayana. Vol. 26. No.2.

Pandi Afandi. (2016). Concept \& Indicator Human Resources Management For Management Research.

Payne, G. T., \& Petrenko, O. V. (2019). Agency Theory in Business and 
Management Research. Oxford Research Encyclopedia of Business and Management, 10.1093.

Purbasari, P. I., \& Yuniarta, G. A. (2020). Pengaruh Kompetensi Sumber Daya Manusia, Budaya Organisasi Dan Pemanfaatan Teknologi Informasi Terhadap Pengelolaan Alokasi Dana. 11(1), 24-33.

Raheni dan Dwija Putri. (2019). Pengaruh Good governance dan Budaya Organisasi pada Kinerja Aparatur Penyelenggara Pemerintah Desa di Kota Denpasar. E-Jurnal Akuntansi. Vol.28.No.2. Hal.1295-1322.

Robbins, Stephen P \& Judge, Timothy A. (2013). Organizational Behavior Edition 15. New Jersey: Pearson Education.

Sugiyono. (2017). Metode Penelitian Kuantitatif, Kualitatif, dan RED. Bandung: A lfabeta.

Tengku Hasan Basri, Iskandar Muda, \& Prihatin Lumbanraja. (2019). The Effect of Profesionalism, Organizational Culture, Leadership Style, Independen on Performance with Intelligence Spiritual as a Variable Moderating on Office Public Accountants in Medan. International Journal of Research \& Review (www.ijrrjoournal.com).

Sugiyono, M. P. P., \& Kuantitatif, P. (2009). Kualitatif, dan R\&D, Bandung: Alfabeta. Cet. VII.

Wardiana, I. A., \& Hermanto, S. B. (2019). Pengaruh Akuntabilitas, Gaya Kepemimpinan, Kompetensi dan di Mediasi Motivasi Terhadap Kinerja Organisasi. 12(1), 129-144.

Wardiana, Arum. (2019). Pengaruh Akuntabilitas, Gaya Kepemimpinan, Kompetensi Dan Motivasi Terhadap Kinerja Organisasi. Jurnal Ilmu dan Riset Akuntansi Sekolah Tinggi Ilmu Ekonomi Indonesia. Vo.8. No.1.

Wahyudi, Agus. (2019). Pengaruh Partisipasi, Akuntabilitas, dan Pemanfaatan Aplikasi Sistem Keuangan Desa Terhadap Kinerja Manajerial Perangkat Desa di Kabupaten Sumbawa. Journal of Accounting Finance, and Auditing Universitas Teknologi Sumbawa. Vol.2. No.1, Pp.65-85.

Yunnita Garung, Lomi Ga. (2020). Pengaruh Akuntabilitas dan Transparansi Terhadap Pengelolaan Alokasi Dana Desa (ADD) Dalam Pencapaian Good governance Pada Desa Manulea, Kecamatan Sasitamean, Kabupaten Malaka. Jurnal Akuntansi Universitas Nusa Cendana. Vol.8. No.1, Hal.19-27.

Yamin, M. (2014). Pola Budaya dan Kinerja Organisasi Publik (Studi Pada Pemerintah Kota Kendari). Jurnal Birokrasi Ilmu Administrasi Publik.

Yilmaz, E., Ozer, G., \& Gunluk. M. (2014). Does organizational politics and organizational commitment influence the creation of budget gaps in public organizations?. Procedia Sosial and Behavioral Sciences, 150, 241-250.

Zelmiyanti. (2016). Pendekatan Teori Keagenan Pada Kinerja Keuangan Daerah Dan Belanja Modal (Studi Pada Provinsi di Indonesia). JRAK. Vol.7.No.1. 